\title{
Perceptions and Experiences Regarding the Current Market System by Communal Farmers in Mhondoro-Mubaira (Zimbabwe)
}

\author{
Evans Muchesa $^{1}$, Douglas Nkosi ${ }^{2}$, Elliot Zwane ${ }^{1}$, Johan Van Niekerk ${ }^{1}$ \\ ${ }^{1}$ Centre for Sustainable Agriculture, Rural Development and Extension, University of Free State, Bloemfontein, South Africa \\ ${ }^{2}$ Department of Animal Production, Agriculture Research Council, Centurion, South Africa
}

Email address:

e.muchesa@gmail.com (E. Muchesa),dnkosi@arc.agric.za(D. Nkosi), elliot.zwane@ul.ac.za(E.Zwane),

vNiekerkJA@ufs.ac.za (J.V.Niekerk)

\section{To cite this article:}

Evans Muchesa, Douglas Nkosi, Elliot Zwane, Johan Van Niekerk. Perceptions and Experiences Regarding the Current Market System by Communal Farmers in Mhondoro-Mubaira (Zimbabwe). International Journal of Sustainable Development Research.

Vol. 4, No. 2, 2018, pp. 31-35. doi: 10.11648/j.ijsdr.20180402.13

Received: August 14, 2018; Accepted: September 1, 2018; Published: September 19, 2018

\begin{abstract}
The objective of this research was to ascertain the communal farmers' perceptions and experiences regarding the current communal market system. The study was carried out in the area of Mhondoro-Mubaira, situated in Mashonaland West province of Zimbabwe. The population samples for the study comprised of communal farmers $(\mathrm{N}=150)$ and extension officers $(\mathrm{N}=25$. According to the study, private buyers are the most preferred buyers for all the produce, for field, garden crops and livestock. The reason for favorable rating of the private buyers is they offer competitive prices, they pay the farmers on delivery of produce and sometimes they cover transport costs. Even though the private buyers are the most preferred buyers, farmers still prefer selling produce between themselves and the open market because they have control of the prices especially for livestock. The Grain Marketing Board and the Cold Storage Commission, which are government run, are the least favorable markets for the farmers. This is because these institutions offer the lowest prices, they do not pay on delivery and offer any assistance to the farmers regarding transport/transport costs. The results show that the farmers are not satisfied with the of the current market system which they deem restrictive, minimally supported by the government, low participation by the private sector, and the current economic situation in Zimbabwe overburdens the situation. The government of Zimbabwe needs to create a conducive environment for private players to participate with government interferences through overburdening policies.
\end{abstract}

Keywords: Marketing, Communal Farmers, Grain Marketing Board (GMB), Mashonaland West

\section{Introduction}

The aim of the research was to ascertain the communal farmers' perceptions and experiences regarding the current communal market system. Most studies such as: [1-7] have shown that lack of access to markets, minimal access to financial assistance, high transaction costs, poor infrastructure, such as roads and market, and lack of comprehensive information about existing individual farmer, farmer organisations or unions profile, and lack of access to appropriate information, technology and extension services, makes communal market system unattractive and limit farmers` participation [10]. Many communal and smallholder farmers face a range of barriers that limit their ability to participate in markets. Against this background, this research looks at the perceptions and experiences regarding the current marketing system by communal farmers in Zimbabwe [10]. Identification of pull and push factors of a market is critical in developing appropriate interventions for the communal farmers. By ascertaining the perceptions of the farmers regarding the market system, we are able to identify the pull and push factors of the markets. The economics on supply and demand using the central theory is an important framework to establish and categorising these factors. 


\section{Hypothesis}

$\mathrm{H}_{0}=$ An improved agricultural market system can improve farmers participation and production.

\section{Conceptual Framework}

Economics on supply and demand using the Central Place Theory. The Central Place Theory (Figure 1) determines the pull and push factors to why farmers would choose a market over others. The Central Place Theory can be a useful tool for the communal farmers, the government and other role players when establishing or choosing a market. The tool can also be useful in ascertaining product types, demand, transport, market infrastructure and prices [8]. The Central Place Theory combined with the concepts of market supply and demand in micro-economics. It is intended to establish up the relationship between market price and distance, through the relationship between market price and commodity quantity [8]
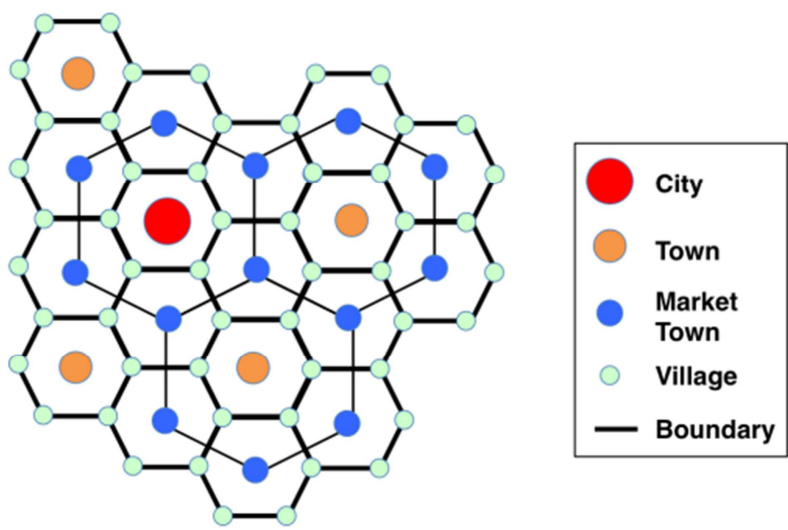

Figure 1. Central Place Theory [8].

Three principles relative to the distribution of the central place theory for the farmers and marketing of their produce and identification of markets are marketing principle, transportation principle and administrative principle. These principles cannot be applied in isolation [10].

(1) Marketing Principle

(2) Central places (a market) usually is established on a location has a response to market forces. A central place is a center that serves an area larger than itself. The area served by a central place/market is its complementary region [9].

(3) Transportation Principle

The transportation strongly influences the location of central places/markets, usually located on one traffic route between two important towns. The route is generally straight and inexpensive to use as possible [9].

(4) Administrative Principle

Administrative services are the primary organizing force on a landscape. The administrative landscapes are also major centres where markets can be established [9] (see Figure 2).

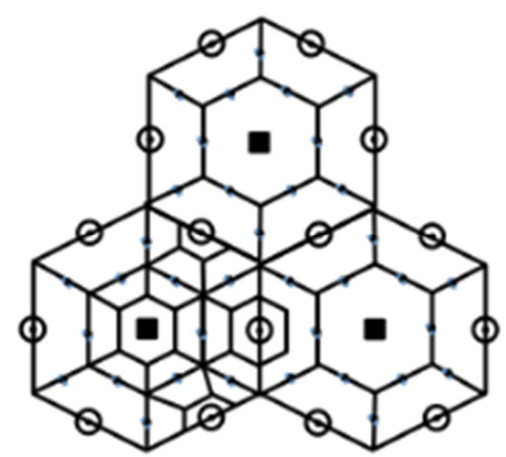

Figure 2. Transportation Principle [8].

\section{Methods}

The target population for the research were communal farmers ${ }^{1}$ and public extension officers located in the Mhondoro-Mubaira which is a constituency in the Chegutu district. The descriptive research interviewed a total of 150 communal farmers and cluster sampling was used. A total of 25 frontline extension personnel was interviewed using convenience sampling. Extension officers were selected on the basis that they work in the Ministry of Agriculture, and they serve under Mhondoro-Mubaira area. The primary data on extension support and agricultural marketing was collected on Section A, B of the Appendix A (Farmers questionnaire) and Section A, B of the Appendix B (extension questionnaire) both structured questionnaires. Semi-structured interviews were done at randomly selected farmer in the Mhondoro-Mubaira communal area. The structure of the questionnaire is composed of Likert scale questions, open ended questions and multiple-choice questions. The data collected from the farmers was captured and coded in MS Excel spreadsheet and cleaned by checking for capturing errors. The Statistical Analysis System (SAS) Statistical 9.4 (2016) package was used to analyze the quantitative data. Chi-square test was used to establish the associations within data. The researcher obtained the required permission from the respondents after informing them about the purpose of the interview and the investigation. Then the respondents were assured that information provided would remain confidential. And the researcher confirmed that participation was voluntary and respondents have the right to withdraw at any time. Furthermore, the respondents were also given the right to ask questions, and obtain further clarity to the questions.

\section{Results/Findings}

\subsection{Communal Farmers Profile}

According to the results women are the largest communal landholders $(68.0 \% ; \mathrm{p}=0.0001)$. The typical land holding per

1 Communal farmers are farmers farming in areas designated has communal farming area according to the communal land act [Chapter 20:04]. Communal farmers constitute almost $50 \%$ of the farmer category in Zimbabwe. Communal areas are generally poorly resourced and poorly supported (Claasens, 2008). 
communal household is between 4 to 5 ha $(66.0 \%$; $=0001)$, and this includes the homestead. $18.7 \%$ of the farmers are above the 60 years, and $40.0 \%$ are in the 51- 60 years age group. A total $68.7 \%$ of the communal farmers are above the age of 50. This is a common age distribution among the communal areas in Zimbabwe. This is because most individuals when they retire from when relocate permanently to the communal areas. Female farmers make up more than $60 \%$ of total farmers in communal areas in MhondoroMubaira area, migration to town or other countries for males is still a dominate phenomenon [11]. The educational level for the communal farmers in Mhondoro-Mubaira communal area, the results show that $73.0 \%(p=0.0001)$ of the farmers have only secondary level education and below. Consideration of educational level for the farmers is important for agricultural extension delivery methods [11].

\subsection{Communal Farmers Perception Regarding the Communal Market System}

The results from the survey are consistent with the three principles of the Central Place Theory of marketing, transportation and administration. Table 1, below shows the major markets and their ratings for the field crops. Most farmers do not view the Grain Marketing Board of Zimbabwe (GMB) as favourable market for the grain crops, $87.34 \%(\mathrm{p}=<.0001)$. Some of the reasons for the poor rating of the GMB include; late payment for the produce; and unattractive prices. The private buyers -company are the most favoured markets as $78.0 \%$ of the farmer's rates $3>$ on 5 -point semantic scale $(p=<.0001)$. The reasons for the favourable include; good prices for the produce; the ability to negotiate for a good selling price.

Some of the identified private buyers company include; Delta, National Foods, National Foods, and Techwiz Services are some of the companies, which buy produce around the Mhondoro-Mubaira area. Open markets are also favorable for the communal farmers with $70.67 \%$ rating them $3>$ on a 5point semantic scale, the main reason being the ability to negotiate for a good selling price. The major markets for the field are reflected in Table 1 below.

Table 1. Major market for field crops (Maize, groundnuts, soybeans) ( $N=150)$.

\begin{tabular}{|c|c|c|c|c|c|c|c|c|c|c|c|}
\hline \multirow{3}{*}{ Market type } & \multicolumn{8}{|c|}{ Ratings } & \multicolumn{3}{|c|}{ Chi-Square Test } \\
\hline & \multicolumn{2}{|c|}{1} & \multicolumn{2}{|l|}{2} & \multicolumn{2}{|l|}{3} & \multicolumn{2}{|l|}{4} & \multirow{2}{*}{$X^{2}$} & \multirow{2}{*}{$d f$} & \multirow{2}{*}{$p$} \\
\hline & $\mathbf{F}$ & $\%$ & $\mathbf{F}$ & $\%$ & $\mathbf{F}$ & $\%$ & $\mathbf{F}$ & $\%$ & & & \\
\hline Grain Marketing Board & 37 & 24.67 & 94 & 62.67 & 19 & 12.67 & 0 & 0 & 61.3200 & 2 & $<.0001$ \\
\hline Private buyers -company & 0 & 0 & 33 & 22.00 & 42 & 28.00 & 75 & 50.00 & 19.5600 & 2 & $<.0001$ \\
\hline Private buyers -Individual & 0 & 0 & 36 & 24.00 & 108 & 72.00 & 6 & 4.00 & 109.9200 & 2 & $<.0001$ \\
\hline Open Markets & 0 & 0 & 44 & 29.33 & 79 & 52.67 & 27 & 18.00 & 28.1200 & 2 & $<.0001$ \\
\hline
\end{tabular}

Table 2, shows the reasons for the ratings for the major market for field crops rated according to priority. According to the results most farmers felt good prices for the produce $(26.42 \%)$ has the biggest motivator for choosing a market, poor prices/unattractive prices $(20.13 \%)$ are a major deterrent for farmers in choosing a market. The third major deterrent is high transport costs $(19.50 \%)$, farmers indicated that if the market is far and transport costs are high, even if the prices are good, the market then becomes less appealing.

Table 2. Reasons for the ratings on major market for field crops $(N=150)$.

\begin{tabular}{lll}
\hline & Freq & \% \\
\hline Unattractive prices & 32 & 20.13 \\
Late payment & 13 & 8.18 \\
Good prices for produce & 42 & 26.42 \\
You can negotiate for good selling price & 20 & 12.58 \\
High transport costs & 31 & 19.50 \\
Poor facilities at the market & 21 & 13.21 \\
Total & & 100 \\
\hline
\end{tabular}

Table 3, below shows the rating for the major markets for the garden crops. The farmer rated the private buyers' companies favorably $92.0 \%(\mathrm{p}=<.0001)$. The private buyers generally offer good prices for the produce and some of them are food processors. The other major market for garden crops is the open markets with the biggest one being Mbare Musika in Harare. The rating for the open markets for the garden crops which are mainly horticultural crops is low with all of the farmers rating $<2$ with a statistical significance of $(p=0.0006)$.

The communal agriculture in Zimbabwe is still the major engine for rural growth and livelihood improvement. Communal farmers in depend on vegetable production has a major household income contributor. It increases farmers' access to cash to spend on clothes, school fees, inputs and promoting farm production [12]. Vegetable production therefore ensures food security, employment and income generation in rural areas, thereby reinforcing the overall development and poverty reduction goals in most countries. In the last decade, Zimbabwe's smallholder horticultural production expanded with the vegetable sector taking a lead [13]. About $60 \%$ of all locally marketed vegetables are produced by communal farmers, contributing between US\$150 and 200 million [14].

Table 3. Major market for garden crops $(n=150)$.

\begin{tabular}{|c|c|c|c|c|c|c|c|c|c|c|c|c|c|}
\hline \multirow{3}{*}{ Market type } & \multicolumn{8}{|c|}{ Ratings } & \multicolumn{5}{|c|}{ Chi-Square Test } \\
\hline & \multicolumn{2}{|c|}{1} & \multicolumn{2}{|l|}{2} & \multicolumn{2}{|l|}{3} & \multirow[t]{2}{*}{4} & & \multicolumn{2}{|l|}{5} & \multirow{2}{*}{$X^{2}$} & \multirow{2}{*}{$d f$} & \multirow[b]{2}{*}{$p$} \\
\hline & $\mathbf{F}$ & $\%$ & $\mathbf{F}$ & $\%$ & $\mathbf{F}$ & & & & $\mathbf{F}$ & $\%$ & & & \\
\hline Private buyers -company & 0 & 0 & 12 & 8.00 & 108 & 72.0 & 29 & 19.3 & 1 & 1.0 & 187.3333 & 3 & $<.0001$ \\
\hline Private buyers -Individual & 0 & 0 & 68 & 45.3 & 51 & 34.0 & 31 & 20.7 & 0 & 0 & 13.7200 & 2 & $<.0001$ \\
\hline Open Markets & 54 & 36.0 & 96 & 64.0 & 0 & 0 & 0 & 0 & 0 & 0 & 11.7600 & 1 & $<0.0006$ \\
\hline
\end{tabular}


The table 4, below shows the reasons for the ratings on the garden crops. Also, good prices for the produce are the main motivator for the farmers when choosing a market, 33.97\% of the farmers indicating as a reason for their rating. The ability to negotiate for a good selling price for the produce also is a motivator when farmers are choosing a market. Unattractive prices are a major deterrent for the farmers, when choosing a market.

Communal garden crops production operations are relatively small, crop diversity is limited (green maize and tomatoes dominate), with problems of production gluts [15]. Although some more established enterprises have begun to diversify, seeking out niche markets, and managing production to take advantage of seasonal production and price cycles [16]. A market garden is generally small-scale production vegetables, and perennial fruits for cash crops, generally sold directly to consumers or open market systems. The assortment of crops grown is on small area of land, typically, from under one acre (0.4 ha) to a few acres [18]. The reasons given by the farmers are typically problems associated with selling directly to the customers and selling on an open market with less regulation [19].

Table 4. Reasons for the ratings on major market for garden crops $(N=150)$.

\begin{tabular}{lll}
\hline & Freq & \% \\
\hline Unattractive prices & 34 & 21.79 \\
Late payment & 17 & 10.90 \\
Good prices for produce & 53 & 33.97 \\
You can negotiate for good selling price & 20 & 12.82 \\
High transport costs & 16 & 10.26 \\
Poor facilities at the market & 16 & 10.26 \\
Total & & 100 \\
\hline
\end{tabular}

Table 5, below shows the major markets for the livestock and poultry. Most communal farmers buy from each other livestock and poultry with $87.33 \%$ indicating $3>$ on a 5-point semantic scale with a statistical significance of $\mathrm{p}=<.0001$. Private buyers -individuals offer a good platform to negotiate good selling prices. Governmental/ parastatals are faced with the same problems, which include late payments and poor prices, which are a major deterrent for the farmers to these markets.

Table 5. Major market for livestock and poultry $(N=150)$.

\begin{tabular}{|c|c|c|c|c|c|c|c|c|c|c|c|}
\hline \multirow{3}{*}{ Market type } & \multicolumn{8}{|c|}{ Ratings } & \multicolumn{3}{|c|}{ Chi-Square Test } \\
\hline & \multicolumn{2}{|c|}{2} & \multicolumn{2}{|l|}{3} & \multirow[t]{2}{*}{4} & & \multirow[t]{2}{*}{5} & & \multirow{2}{*}{$X^{2}$} & \multirow{2}{*}{$d f$} & \multirow{2}{*}{$p$} \\
\hline & $\mathbf{F}$ & $\%$ & $\mathbf{F}$ & $\%$ & & & & $\%$ & & & \\
\hline Private buyers -Individual & 19 & 12.7 & 113 & 75.3 & 18 & 12.0 & 0 & 0 & 119.080 & 2 & $<.0001$ \\
\hline Government/Parastatals & 122 & 81.3 & 28 & 18.7 & 0 & 0 & 0 & 0 & 58.9067 & 1 & $<.0001$ \\
\hline
\end{tabular}

Table 6, below shows the reasons for the ratings on the major markets for livestock and poultry. Most farmers feel that high transport costs are a deterrent when choosing a market; this is because transporting livestock is expensive. So, when selling livestock established local sells/markets are mostly preferred. Late payments from Cold Storage Commission which is now operating at a sub-minimum and as a private entity prevents farmers selling their livestock on such market. Texas Meats, Surrey and MC Meats are some of the private companies which buy livestock, but none of the farmers indicated they are aware of any of them, which means they have no coverage in the Mhondoro-Mubaira area [19].

Table 6. Reasons for the ratings on major market for livestock and poultry $(N=150)$.

\begin{tabular}{lll}
\hline & Frequency & \% \\
\hline Unattractive prices & 24 & 15.09 \\
Late payment & 28 & 17.61 \\
Good prices for produce & 22 & 13.84 \\
You can negotiate for good selling price & 20 & 12.58 \\
High transport costs & 42 & 26.42 \\
Poor facilities at the market & 23 & 14.47 \\
Total & & 100 \\
\hline
\end{tabular}

Table 7, shows the major challenges in accessing the markets by the farmers rated according to priority. The farmers indicated that finance $(28.13 \%)$ has one of their major in accessing the markets. Finance affects production levels, so farmers are not able to produce enough so that they can sell or push enough volume. So, this remains a challenge as farmers cannot produce enough so that they can sell. This is followed by expensive transport costs $(25.63 \%)$, most farmer do not access good markets, which are as far as Harare despite good produce prices because of the high transport cost. This is the coupled by poor market facilities $(19.38 \%)$ and poor road infrastructure $(10.63 \%)$, these factors compounds the expensive transport costs by adding additional costs. Poor market infrastructure especially at open markets at Mubaira Growth Point or in Norton exposes the farmers to unscrupulous and unregulated traders.

Table 7. The major challenges in accessing markets $(N=150)$.

\begin{tabular}{lll}
\hline & Frequency & \% \\
\hline Unavailability of information on markets options & 20 & 12.50 \\
Poor quality of produce & 6 & 3.75 \\
Poor road infrastructure & 17 & 10.63 \\
Expensive transport costs & 41 & 25.63 \\
Finance & 45 & 28.13 \\
Poor facilities at the markets & 31 & 19.38 \\
Total & & 100 \\
\hline
\end{tabular}

\section{Conclusion}

According to the study, the average farm size for the communal farmers is between 2 and 5 hectares $(66.0 \%)$. Land size is factor that limits farmers to engage in a number of farming enterprises. Farmers with more land are more likely to stagger their production to ensure all-year supply of produce. The results also show that women are the biggest landholders, this means government by addressing the needs 
of the communal farmers (whom are the most marginalized), inherently address and uplift women in the country. $68.7 \%$ of the farmers are above the age of 50, this means labour for activities that are more strenuous are limited. This means that agricultural activities, which are not labour intensive, are the most preferred by the farmers [11].

According to the farmers, private buyers are the most preferred buyers for all the produce, for field, garden crops and livestock. The reason for favorable rating $\mathrm{pf}$ the private buyers is they offer competitive prices, they pay the farmers on delivery of produce and sometimes they cover transport costs. Even though the private buyers are the most preferred buyers, farmers still prefer selling produce between themselves and the open market because they have control of the prices especially for livestock. The Grain Marketing Board and the Cold Storage Commission, which are government run, are the least favorable markets for the farmers. This is because these institutions offer the lowest prices, they do not pay on delivery and offer any assistance to the farmers regarding transport/transport costs. The government needs to improve the service delivery of these institutions and offer competitive prices. Addressing the farmers ' major challenges in accessing the markets, expensive transport costs, poor road infrastructure and other related market infrastructure will significantly improve the market opportunities for the communal farmers in Zimbabwe [19].

The results show that the farmers are not satisfied with the of the current market system which they deem restrictive, minimally supported by the government, low participation by the private sector, and the current economic situation in Zimbabwe overburdens the situation. The government of Zimbabwe needs to create a conducive environment for private players to participate with government interferences through overburdening policies. The government also needs to invest in communal market infrastructure such as roads, market places and regulate the open market system.

\section{References}

[1] Naziri, D., Rich, K.M. and Bennett, B. (2015). Would a commodity - based trade approach improve market access for Africa? A case study of the potential of beef exports from communal areas of Namibia. Development Policy Review, 33(2), pp.195-219

[2] Muchesa, E. (2013). Sustainable extension support to land reform beneficiaries in Zimbabwe (Mashonaland West) (Masters dissertation, University of Pretoria).

[3] Köhler, H., \& Link, S. (2018). SQL schema design: foundations, normal forms, and normalization. Information Systems, 76, 88-113.

[4] Makhura, M. N., Mdluli, M., \& Senyolo, G. M. (2006). Development Indicators of Emerging Farmers of South Africa, Survey 2006. DBSA Research Report.

[5] Ndokweni, M. F. (2002). Improving sustainable livelihoods through organic produce marketing opportunities: evaluation of the Ezemvelo Farmers Organisation.
[6] Mthembu, N. (2005). Survival Strategies of Individuals and Households Affected by Unemployment in the Ethekwini Municpality. Durban: Centre for Civil Society RASSP Research Reports, 1, 2.

[7] Machethe, C. L. (2004). Agriculture and poverty in South Africa: Can agriculture reduce poverty. Paper presented at the DBSA/HSRC/UNDP. Conference on overcoming underdevelopment in South Africa's second economy. Pretoria 28-29 October 2004.

[8] Murphy, R. E. (2017). The central business district: a study in urban geography. Routledge.

[9] Bell. M, Hotchkiss. P. (1991). Garden cultivation, conservation and household strategies in Zimbabwe, Cambridge.org.

[10] Bloom, K. (2009). Social safety nets: learning from best practice. Presentation. Asian Development Bank (available at http://www.adb.org/.

[11] Carter.SE, \& Murwira. H.K. (1995). Spatial variability in soil fertility management and crop response in Mutoko Communal Area, Zimbabwe- JSTOR.

[12] Cousins.B. (1993). Property and Power in Zimbabwe's Communal Lands: implications for Agrarian Reform in the 1990`s. University of Zimbabwe. http://dlc.dlib.indiana.edu/dlc/bitstream/handle/10535/3706/co usins property and power in zimbabwes communal lands implications for agrarian reform in the 1990s.pdf? sequence $=1$.

[13] Esther M. Kihoro. P.I, Nyikal. R, \& Maina. I.N. (2015). An analysis of factors influencing farmers' choice of green gram marketing channels in Mbeere south sub-county, Kenya. http://ageconsearch.umn.edu/ bitstream/249331/2/198.\%20Factors\% 20influencing\%20marketting \%20in\%20 Kenya.pdf.

[14] Hurungo, J. (2007). Zimbabwe's Look East Policy: Pros and cons. Harare: Trade and Development Studies Centre.

[15] Makhura. M. T. (2001). Overcoming transaction costs barriers to market participation of smallholder farmers in the Northern Province of South Africa. Unpublished $\mathrm{PhD}$ thesis. Department of Agricultural Economics, Extension and Rural Development. Pretoria: University of Pretoria.

[16] Mhazo N, Hanyani-Mlambo B, Proctor S, and Nazare R.M. (2001). Constraints to small scale production and marketing of processed food products in Zimbabwe. [WWW document]. URLhttp://foodafrica.nri.org/enterprises/ enterprisespapers/ SharonProctor.doc.

[17] Moyo, S. (2009). The land and agrarian question in Zimbabwe. In Buthelezi, S. (ed) The land belongs to us: The land and agrarian question in South Africa. Alice, Fort Hare University Press.

[18] Mutibvu. T, Maburutse. BE, \& Mbiriri. DT. (2012). Constraints and opportunities for increased livestock production in communal areas: A case study of Simbe, Zimbabwe - Livestock Research, 2012 - researchgate.net.

[19] Nel.E \& Davies. (2015). Farming against the odds: an examination of the challenges facing farming and rural development in the Eastern Cape province of South Africa. Department of Geography, Rhodes University, Grahamstown, South Africa, Department of Geography, University of Wales: Swansea, Singleton Park, Swansea SA2 8PP, UK. 